\title{
Analysis of the Anti War Thought from Animated Film
}

\author{
WANG Hongwei \\ Arts and Media College \\ China University of Geosciences \\ Wuhan, China \\ e-mail: houxw3000@163.com
}

\begin{abstract}
Art comes from life, so the artist's life experience will affect his creation. Hayao Miyazaki is so, living in the era of war, witnessed the brutal war, about the horrors of war. This is Hayao Miyazaki's childhood life experience. This is Hayao Miyazaki's childhood life experience, so it is also created his anti war thought.
\end{abstract}

Keywords-Hayao Miyazaki; the anti war thought; causes; performance; animation film

\section{INTRODUCTION}

Artistic creation is inseparable from the creator of the era of life and cultural traditions. As Dana said: "the artist itself, along with all of his works, also is not isolated. There is a general, including artists, the wider than artists, is what he is, but at the same time with the art of sectarian or art family." Also include "art of the family itself within a larger overall, is around it and consistent interest and his society." One can't avoid to live in a particular cultural tradition. Affected by specific cultural tradition and The Times. The creation of the animation master hayao miyazaki is also influenced by their own time and culture. If based on the relationship between man and nature thinking form the hayao miyazaki's ecological view of anthropocentrism. So influenced by Japan's political, economic, cultural, witnessed the war to the state and the destruction of human civilization, has contributed to his anti-war thought the reason.

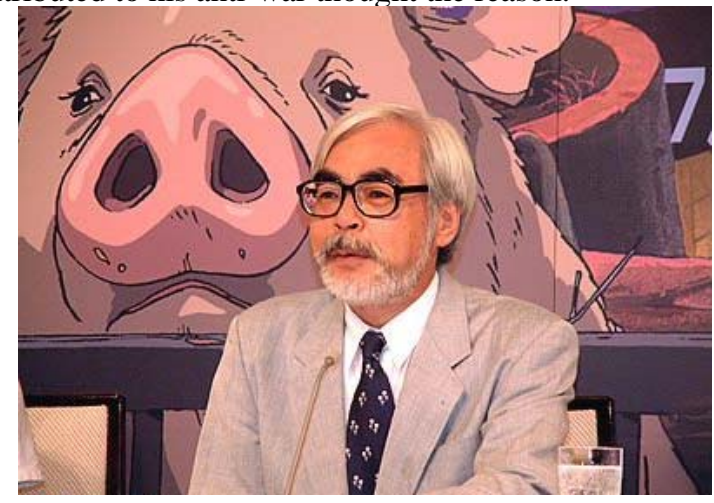

Figure 1. Hayao Miyazaki.

\section{THE CAUSE OF HAYAO MIYAZAKI ANTI-WAR THOUGHT}

Wherever Times is specified, Times Roman or Times New Roman may be used. If neither is available on your word processor, please use the font closest in appearance to
Times. Avoid using bit-mapped fonts if possible. True-Type 1 or Open Type fonts are preferred. Please embed symbol fonts, as well, for math, etc.

Hayao miyazaki knows the ugliness of war, so drew a lot of works of world war ii, is particularly important is that he painted the Chinese air force air strikes Japan for the first time. In this work, he said: "Martin is not contained in the bomb, is to accuse the Japanese atrocities, arouse the conscience of the Japanese people, cast is leaflets also hope that the Japanese people have seen how much these flyers should have some action against the war. However, the next day the newspapers only very small a message:" appeared in the sky kyushu mysterious bomber............ "Just so, the Japanese continued to expand the war, however, indiscriminate bombing of chongqing have long.

After watching the film to hayao miyazaki admiration arises spontaneously, hayao miyazaki and pat thought those people and of the men, although anti-war but just from the Japanese perspective, by rendering tragic war against Japanese, but see from the work, hayao miyazaki on have a deeper understanding of the war, perhaps the hayao miyazaki's air force bombed Japan town in China, if the plane is throwing bombs maybe today can't see so many wonderful works, not all Japanese forgetfulness, if paper bombing have what results, that is the tolerance to the Chinese moved by a master of animation.

Hayao miyazaki exactly how to think about the war, but we don't know, because he said was not clear, but we can see from many of his works in his anti-war clues.
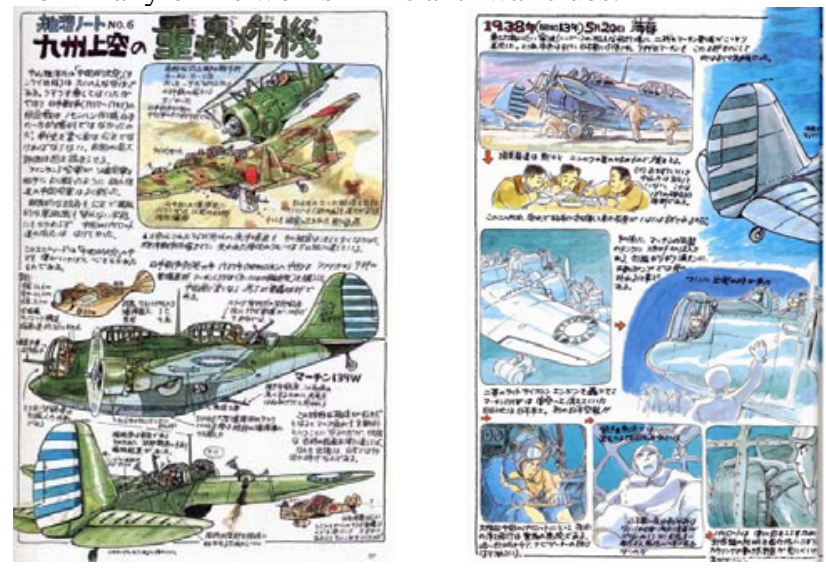

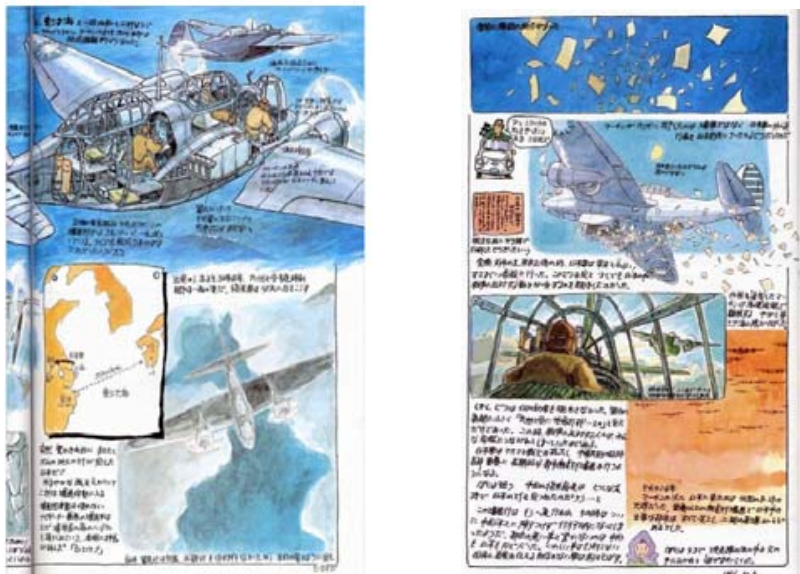

Figure 2. First Chinese Air Force after the Japanese air raid.

\section{HAYAO MIYAZAKI ANTI-WAR THOUGHT IN THE WORK PERFORMANCE}

\section{A. Flying red pig}

"Red pig" wave of Luke is the best portrayal of hayao miyazaki's own anti-war thought. "Red pig" and other "province" consciousness hayao miyazaki's works, he is the most "examination of self consciousness" half a biography movie, the movie depicts a he who sees through the world of mortals and cynical personal image.

Red pig was not a pig, it is a former Italian air force a hero, a lifetime love flying wave Luke, when he realized after the rise of fascism, he chose to leave, he will fly according to their wishes, in order not to let others recognize her he put himself into a pig, hayao miyazaki's ideas are always so interesting, the hero in the ordinary people eyes always have done some things that ordinary people can't stand a but he this idea is really too eccentric, maybe has something to do this and the Japanese culture. And in order to avoid the fascist recruitment turned himself into a pig, and this itself shows that dislike of fascist hayao miyazaki, the protagonist's behavior also showed his dislike of war, when he told the pilot duel, when he high-explosive incendiary weapons dealer recommended he take only the ordinary bullets, then told him it was a duel is not war, fight a duel with is there a difference? Seems only mortal, but he thought he felt, one is based on the national and ideological war and based on human nature, one is the men to fight for money and love in the male, an oneself to choose to kill or not kill, one can only be a meat killing machines. Hayao miyazaki is a contemporary art anarchists, in his eyes, all good things, such as love, friendship, support each other in trouble, all from individual, rather than their. And countries are always the evil and the ugly, only when countries temporarily exit, the beautiful journey and story to unfold, once the country's face appeared in the sky, it means that a good story to an end.
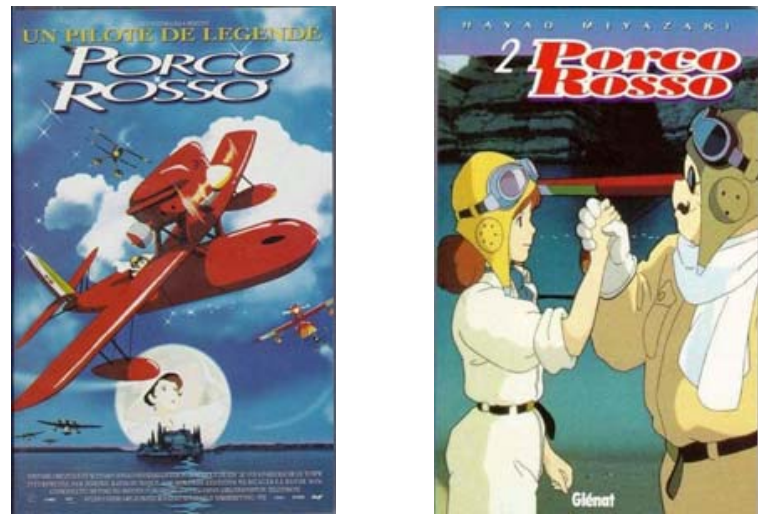

Figure 3. Movie of Red pig

In the work of civilian life very meticulous description in the war, when pay wave Luke, he from a large portfolio of take out a lot of big pile of money, is filled with the boss's desk, but the boss or is insufficient, because the inflation. Before the second world war the inflation and economic depression is undoubtedly the rise of fascism and militarism main social background, also is certainly experience generation of bitter memories.

Hayao miyazaki has said interpretation, this is the animation, film shooting to adults see and theme is not consistently argued, is a "'" should not do work. Has been explored the "nature and humanity" relations in pursuit of spiritual balance, hayao miyazaki film to be near entertainment direction, subject to the "about middle-aged spiritual liberation" level. "Red pig" comedy, tragedy to reflect the hayao miyazaki of reality is helpless, and laugh at themselves. Everyone has a dream, have a passion for air flight hayao miyazaki maybe had really hope in a youth to become pilots fly freely like a wave of Luke Russell, you never know, however, lay in him for local war and Japanese society filled with concern and there is no way to deal with. Treatment of frustration and annoyance is self-deprecating, hayao miyazaki and concrete is reflected in two aspects. One is the image of comedy, in hayao miyazaki's view, "when a middle-aged man, he became a pig." The beginning, "red pig" was identified as "a letter to a dean as excessive brains into tofu, middle-aged businessmen funny movie". Although the story is more serious than he expected, but wave elder brother is a pig face, middle-aged fat, lazy, rude and stupid, is an elegant male supremacist at the same time, from the image itself has a sense of comedy. Wave Luke dissatisfied with the reality, in the midst of a military wanted, at the same time is the thief panic in the free. It was a tragic hero extremity story, but the image of the bokor comedy hayao miyazaki, has the flavor of the "black humor". Secondly, the war game. The first world war although the plane into a brutal murder tool, but also trained a large number of pilots. When the war ended, the consortium, the government and media have focused on the sky adventure, flying continuously held all kinds of competition, high bonuses and reputation makes planes in mechanical technology and driving two-sided increase rapidly. In the age of full of adventure, try, don't know have how many adventurers lost 
due to flight life, but also create numerous records and found that air. And a new era of war, just like the adventure race, is full of weird fearful of high-tech war, lack of reality, it is a kind of a series reports on TV like the game of death.

The red pig frolic in the medium wave Luke and empty thief air combat, bullets, smoke spread, but a life also have no loss, and finally the winner also leave half of the money as failure repair, let a person feel full of the flight of chivalry world is an era of full of faith and the game of life. The film in addition to paint a middle-aged man's dream, at the same time memory of a great flying golden age and dislike of war.

"Red pig" is often forgotten in the works of hayao miyazaki film, but he really spent a lot of effort, not just his painting life work, more is his analysis of the self. In the country, age, life significance of these serious proposition, he created a "cool pig" image of the contradictions in any doubt. Do not lose the essence of cartoon culture and contain is worn for war, and time thinking and criticism.
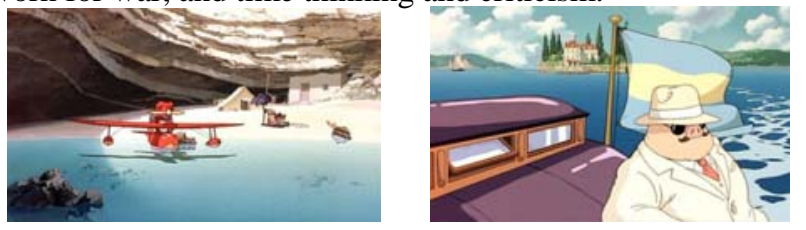

Figure 4. Movie scene of Red Pig.

\section{B. The city of the sky}

What is the most prominent hayao miyazaki? The plot of moving? Rich imagination? Beautiful painting style? Noble character? Is not, perhaps the most outstanding, is the leading lady in all his works are not the big beauty, but each heroine is popular, in "the day the city of empty," small gu niang tower is the legendary rapp of human origin, after the rapp da who is over the earth civilization civilization thousands of years of air. But somehow, tower's ancestors left "sky city", abandon the developed science and technology, on the ground a reclusive life. Investigate its reason, the development of human civilization pinnacle "sky city", although is the masterpiece of high-tech, in fact has become a not suitable for human habitation, leaving only two kind of robot watch, although flowers, inaccessible, however, was silent. So the fine structure, but as long as a spell, then suddenly fall apart. And aspirant mousse card took him, just want to use its power to conquer the world, is arrogant and arrogant.

Hero life in the city of the sky in the European town of industrial revolution, really let a person enchanted environment, hayao miyazaki's animation always give a person a kind of mechanical aesthetics, he indulged in performance, always when vigorous development of the industrial age is novel and marvel at the beauty of the mechanical, this kind of beauty is not the silver in the Star Wars in the future, but the era of industrial rise plain, rough process of the steel, in today's industrial society after the silicon, the rough clumsy machinery has been basically vanished, they rumbled or drops of sound, face dirty, temperament is plain old industrial workers, as well as the era of Marx in London or New York image, drifts away from the urban and suburban green mountains mass of black smoke could have for today's people, a man should have experience with all kinds of mechanical toys as a child, the boys was originally a gift, toys and tinkering with the machinery of surprise and happiness, and let every adult was delicious, it was a full of dreams, wisdom and the creation of good memories, is also a country opens the door to the industrialization of the future, every time he put them to the front of the audience, the audience was intoxicated among them can't from pull out.

Each time saw the steam engine has a feeling of pilgrimage, because always let a person feel the industrial revolution is the longmen human jump, in his before and after the power of human transform nature got a qualitative leap, the small and weak in the presence of natural human suddenly became a giant, a huge power of human history, man can conquer nature has become the era theme, show the Eiffel Tower is the era of human power, prove that man can conquer nature memorial symbol (all made from iron and steel industrial strength), humans have a strength, not afraid of nature, the human was afraid of what? Most afraid of similar to human energy is spent on how to slaughter of the same kind, the original nature, human and the basis of the united front, sidelined now nature, human beings can open hand similar massacre, especially now that mankind has a great power, the slaughter of more simple, but the purpose of the human is no best, only better so even existing weapons have been easy to slaughter humans still towards faster and more fierce, the direction of exploring the less human nature.

Once the brilliant sky city with a very advanced science and technology, but the civilization disappeared overnight, his people no longer go back on the ground, seclusion its wealth unclaimed left in the sky, leaving no one believes a legend, but some believe, for its untold riches, developed science and technology, and invincible weapon, even if it means dying. So colorful characters and infighting very lively, but in the end the sky city still belong to his master hilda, greedy JiaYiChang all for her.

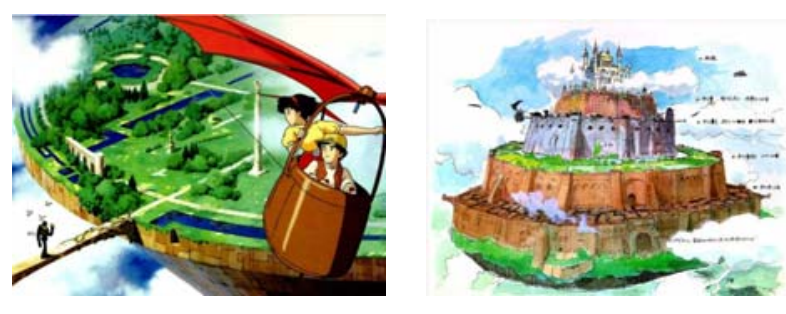

Figure 5. Movie of sky city.

Hayao miyazaki's animation, it doesn't always recruit people like army, the military in the "red pig" persistently call leading role to serve again, "sky city" in the army played a negative role, directly when the leading role by the army to rescue from the pirates they find themselves out of the den and into the jaws, the army's chief of greed and violence, and remember the letters from iwo jima, leading role has said the military police grab anything, bread, brown sugar, flour, even baked bread plate will take away, the last hero himself sent to iwo jima that desolate place. Although he didn't say 
this is the Japanese army, but both image and as with the Japanese troops, and spy chief vladimiro moose card is more like a politician, more cunning than the army chief, fat he, as a heroine and hidayat as "the city of the sky rapp" royal descent, advanced science and technology are after his forefathers and invincible weapon, with these, the revitalization of rapp clan, to conquer the world will be easy, but with no let him satisfied, a spell self-destruct the weapons and the control center of the city, leaving only "the tree of life" is "sky stone" carrying lonely at the end of the curling into the sky.

In these thick and thus suggesting a picture of a meaning, see is hayao miyazaki constantly reminded human don't prided himself, can't stand on the top of the food chain and ignore the existence of other species, and to wage war, in the end will be the consequences.

Have seen a lot of film, the army and pirate theme early clap lousy, but miyazaki dug up in the traditional new, traditional films or army positive, positive either pirates, and the sky of the city is neither army when positive nor pirates when positive, positive just men and women protagonist, and opposite also only spy chief vladimiro moose, army and pirates just in pursuit of wealth and erroneously promote the development of the plot.

Hayao miyazaki is old, but still hope in his lifetime, he can give us some surprises, no colorful packaging can attract people, but not geared to the needs of the audience attracted all the audience, not boring lecture but thought-provoking, let us know what is master hayao miyazaki.
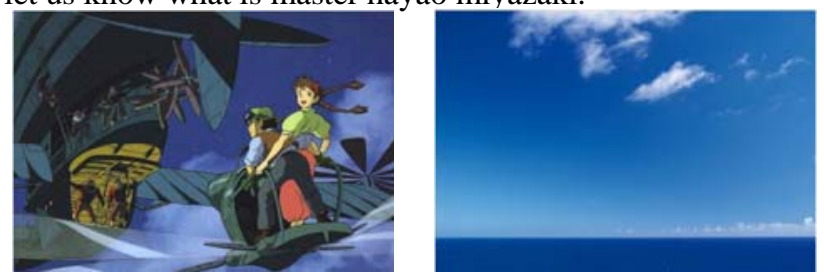

Figure 6. Movie scene of sky city.

\section{CONCLUSION}

Have comments like westerners hayao miyazaki: "life in the west of us, when the first time that hayao miyazaki, is he in the film completely attracted by the romantic and kind heart. But if you spend some time to research his pinter don't is such as" the valley of the wind "' Hal mobile city fort", you will send now the palace battery jun is a body of spear shield in the house of art. One side surface, I see his love for since then, his motivation to advocate righteousness, and the other outside the party, but I could see the doubt and coward. His pessimism and realism." But this doubt and flint, pessimism and realism is actually hayao miyazaki's ecological view of anthropocentrism, and specific of anti-war thought. Although very disappointed for adult world, hayao miyazaki says he is a pessimist,

The end of the world's scene appeared again and again in his movies, he seems to be the human constantly warning, humans have for their own greed and wickedness paid a heavy price, or will pay a heavy price. But he is not a despairing pessimist, created many brave in the movie, the girls and boys who caring image, they are as clear messianic figure, always made in careerists in human havoc to confront, rely on fearless self sacrifice to save the world, to save humanity. Hayao miyazaki's sadness always failed to suppress hunger for innocence and goodness, believe that man will wake up after suffering from "cursed-by-god", reflect on war, war. In the bottom of my heart, he has a strong salvation of intellectuals thought. He hopes the world will get better, his life ideal is: "I want to be able to once again with more depth work, save the soul of the fall of man."

\section{REFERENCES}

[1] Noriko T. Reider, "Spirited Away: film of the fantastic and evolving Japanese folk symbols,” Film Criticism, 1995, pp. 1271-1350.

[2] Helen McCarthy, "Nayao Miyazaki--Master of Japanese Animation,” Film Criticism, 1999, pp. 1389-1492.

[3] Eleven Lang, “Animationcreation theory," Chen Huili Trans. Tsinghua University press, vol. 15, pp. 330-341, May 2004.

[4] J. Clerk Maxwell, A Treatise on Electricity and Magnetism, 3rd ed., vol. 2. Oxford: Clarendon, 1892, pp.68-73.

[5] I. S. Jacobs and C. P. Bean, "Fine particles, thin films and exchange anisotropy,” in Magnetism, vol. III, G. T. Rado and H. Suhl, Eds. New York: Academic, 1963, pp. 271-350.

[6] K. Elissa, “Title of paper if known,” unpublished.

[7] R. Nicole, "Title of paper with only first word capitalized," J. Name Stand. Abbrev., in press.

[8] Y. Yorozu, M. Hirano, K. Oka, and Y. Tagawa, "Electron spectroscopy studies on magneto-optical media and plastic substrate interface,” IEEE Transl. J. Magn. Japan, vol. 2, pp. 740-741, August 1987 [Digests 9th Annual Conf. Magnetics Japan, p. 301, 1982].

[9] M. Young, The Technical Writer's Handbook. Mill Valley, CA: University Science, 1989. 